\title{
Bilateral symmetrical lipoma of the buccal fat pad as an incidental finding in a woman with weight gain after tamoxifen: a case report
}

In Suk Koh',

Jin Woo Kim ${ }^{1}$,

Ji Young Yun ${ }^{1}$,

Eui Han Chung',

Young Il Yang',

Hook Sun ${ }^{1}$

Departments of ${ }^{1}$ Plastic and Reconstructive Surgery and ${ }^{2}$ Pathology, Busan Paik Hospital, Inje University

School of Medicine, Busan, Korea

\begin{abstract}
Although lipoma is a common benign tumor, it occurs relatively infrequently in the oral and maxillofacial areas, and only 31 cases of lipoma in the buccal fat pad have been reported. Herein, we present an extremely rare case of symmetric lipomas in both buccal fat pads. These masses were incidentally discovered during a facelift procedure in a 50-year-old woman with a 4-year history of tamoxifen use. during which she had gained $10 \mathrm{~kg}$. The patient stated that cheek protrusion had developed concomitantly with weight gain and was exacerbated by an injection lipolysis procedure she had received 1 year previously. This case underscores the importance of paying careful attention to the patient's medication use and surgical history when evaluating suspected cases of lipoma, and sheds light on tamoxifen use and subcutaneous injections of phosphatidylcholine and deoxycholate as potential risk factors for lipoma development.
\end{abstract}

Abbreviations: $\mathrm{DC}$, deoxycholate; PC, phosphatidylcholine

Keywords: Case reports / Face lift / Leptin / Lipoma / Tamoxifen / Weight gain

\section{INTRODUCTION}

Lipoma, which is the most common benign tumor of mesenchymal origin, can occur anywhere adipose tissue is present [1]. Common locations of lipoma are the shoulder, back of the neck, back, thigh, buttocks, and upper arm, while lipoma less frequently occurs on distal extremities and in the craniofacial area. In particular, only $1 \%$ to $4 \%$ of all lipomas occur in the oral and maxillofacial area [2]. Lipoma in the buccal fat pad is particularly rare and underreported, as only 31 cases have been reported [3].

We report a rare case of symmetrical lipomas in the buccal fat pads that were incidentally found during facelift surgery in a 50 -year-old woman with breast cancer. She had been taking

\section{Correspondence: Hook Sun}

Department of Plastic and Reconstructive Surgery, Busan Paik Hospital, Inje

University School of Medicine, 75 Bokji-ro, Busanjin-gu, Busan 47392, Korea

E-mail: sun443@naver.com

Received October 14, 2021 / Revised October 27, 2021 / Accepted December 9, 2021 tamoxifen, and reported that she had undergone injection lipolysis for both cheeks, which has not been effective.

\section{CASE REPORT}

A 50-year-old woman was admitted to the plastic surgery center for facial contour improvement; specifically, she hoped to address a square shape of the face that resulted from protruding cheeks. She was taking tamoxifen as an anti-hormonal treatment after having undergone total mastectomy for left breast cancer 4 years ago. She had gained $10 \mathrm{~kg}$ of weight after starting to take tamoxifen and reported no history of facial trauma. She stated that her cheeks began to protrude as she gained weight. In addition, she complained that her cheeks protruded even more after she underwent injection lipolysis, including 10 injections of phosphatidylcholine (PC) and deoxycholate (DC), at a plastic surgery clinic a year ago for adipose reduction in both cheeks. She visited our department for surgical treatment. We 
planned a facelift under general anesthesia to create an ovalshaped face, along with buccal fat reduction in both cheeks.

Subcutaneous facelift with plication of the superficial musculoaponeurotic system via a pretragal incision was performed. While performing buccal fat reduction after subcutaneous layer dissection, symmetrical masses composed of adipose tissue in both buccal fat pads were incidentally found and total excision was performed (Fig. 1). The operation was completed after performing a superficial musculoaponeurotic system plication suture and excising excess skin. The excised masses were sent for biopsy. The patient had no complications such as hematoma or infection after surgery.

The masses removed from both buccal fat pads were finally diagnosed as lipoma since they showed well-matured lipocytes with intermingled fibrovascular stroma surrounded by a fibrous capsule on a microscopic examination (Fig. 2) [4]. Photographs were taken before surgery, at 1 month, at 3 months, and at 6 months after surgery to evaluate the outcomes. The 6-month postoperative photographs showed an oval shape of the face, and the patient was satisfied with the improved con- tours of both cheeks (Fig. 3).

\section{DISCUSSION}

Lipoma is the most common benign tumor of mesenchymal origin, and it can occur anywhere that adipose tissue is present $[1,5]$. Lipoma is frequently found in the upper and lower limbs, but is uncommon in the head and neck [6]. On clinical examination, lipomas are smooth, well-circumscribed, lobulated, and greasy to the touch, and they show a tendency for slow growth [7]. A definite diagnosis of lipoma is possible when a microscopic examination reveals adult adipocytes in the stroma of connective tissue surrounded by a fibrous capsule $[5,8,9]$.

Burns first described lipoma in the buccal fat pad in 1811 [10], and Cameron published the first review article on lipoma in the buccal fat pad in 1921 [11]. Lipoma in the buccal fat pad is uncommon, as only 31 cases have been reported, and it is thought to be underreported due to its atypical characteristics [4]. Lipoma in both buccal fat pads is particularly rare, as only one other case has been reported [12].
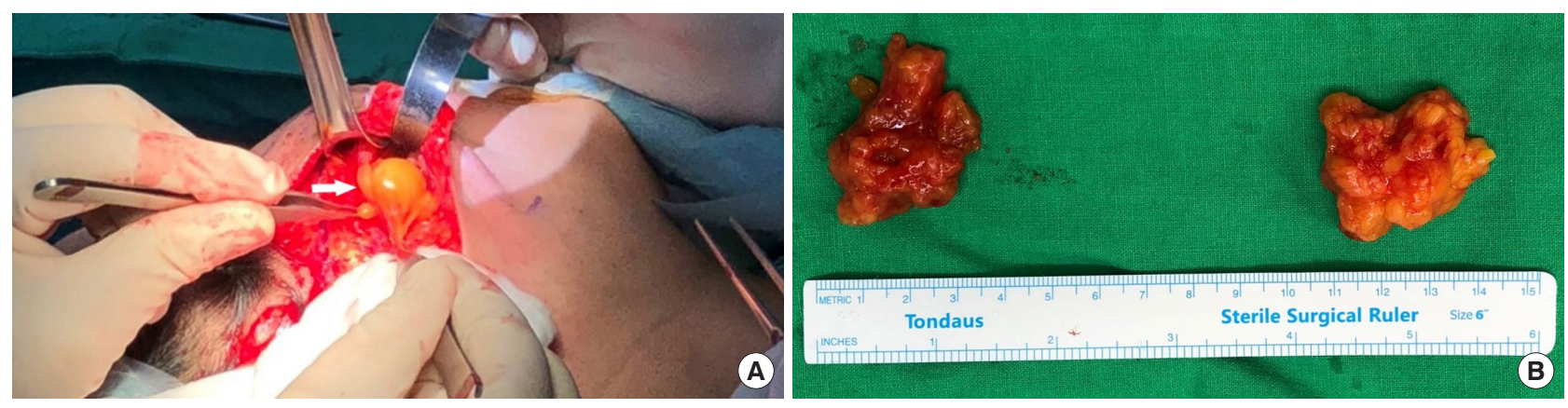

Fig. 1. Intraoperative photographs. (A) A 50-year-old woman with an encapsulated mass in the buccal fat pad composed of adipose tissue (white arrow). (B) Excision of bilateral symmetric masses composed of adipose tissue.
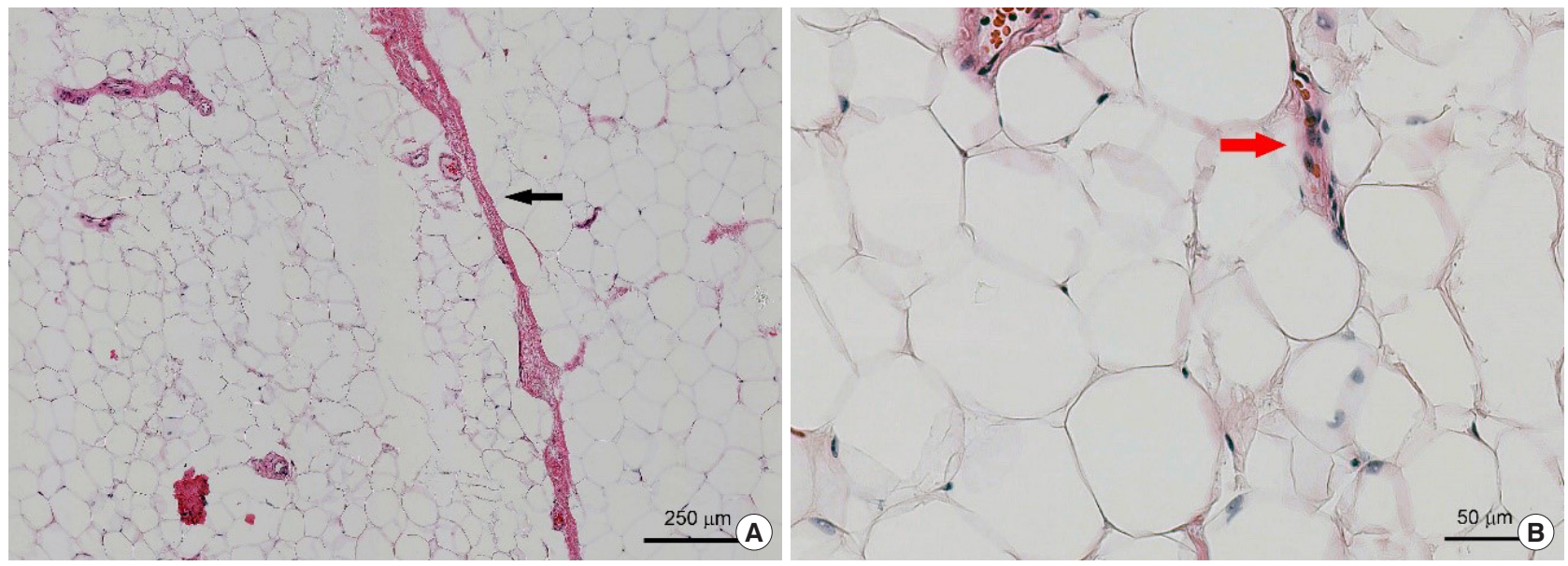

Fig. 2. Histopathologic examination. (A) Low-power view of a well-circumscribed lipomatous lesion (black arrow; H\&E, $\times 40$ ). (B) High-power view of well-matured lipocytes with intermingled fibrovascular stroma (red arrow; H\&E, $\times 200$ ). 

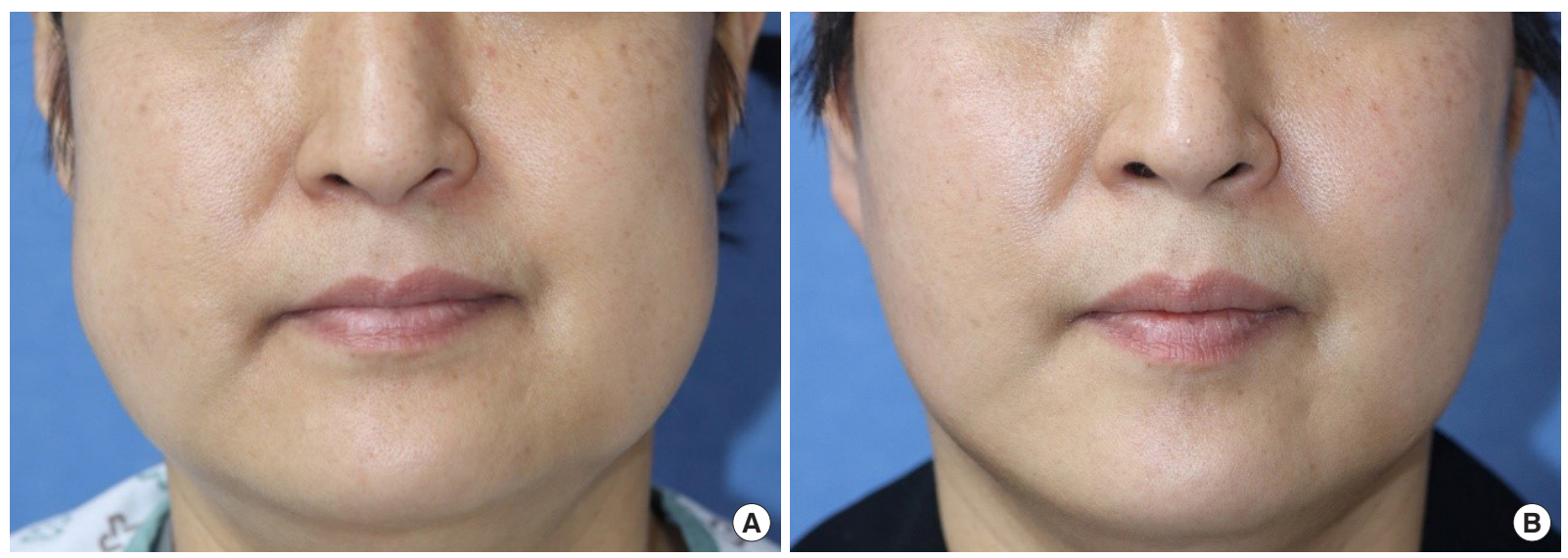

Fig. 3. Preoperative and postoperative photographs. (A) Preoperative photograph; bilateral bulging of the cheeks resulting in a square appearance of the face. (B) Six-month postoperative photograph; the facial contour improved, without bulging.

Although the etiology of lipoma has not been conclusively elucidated, the occurrence of subcutaneous lipoma is related to hereditary factors, obesity, diabetes, radiation, endocrine disorders, insulin injections, corticosteroid therapy, and trauma [1]. The incidence of lipoma is particularly high in people with obesity, hyperlipidemia, and diabetes [13]. The patient in this case complained of cheek protrusion accompanying weight gain after starting to take tamoxifen. Tamoxifen causes malepattern and visceral obesity through anti-estrogenic effects, and its use may be accompanied by fatty liver and hypertriglyceridemia [14].

The gold standard for subcutaneous fat reduction is liposuction, but liposuction of the face is difficult. Some patients also find liposuction burdensome; therefore, injection lipolysis, which has the advantages of less invasiveness and minimal downtime, is useful. PC-DC, the main drug used for injection lipolysis, makes lipids water-soluble and causes fat cell destruction [15]. The patient in this case complained that both cheeks protruded more after receiving subcutaneous PC-DC injections. Subcutaneous injections of PC-DC have been found to reduce the expression of genes related to hormonal activity in adipocytes, such as leptin, adipose triglyceride lipase, and hormone-sensitive lipase [16]. In particular, leptin is a potent stimulator of lipolysis and fatty acid oxidation that regulates lipolysis by controlling the activity of hormone-sensitive lipase [17].

The patient in this case reported no history of diabetes or facial trauma, but stated that she had gained $10 \mathrm{~kg}$ of weight after taking starting to take tamoxifen 4 years ago, during which time cheek protrusion developed. Lipomas are more common in obese persons. Moreover, lipomas tend to present following a period of weight gain and often increase in size during a period of rapid weight gain $[18,19]$. Common tamoxifen attributed side effects were hot flashes, vaginal dryness, sleep problems, weight gain, and depression, irritability or mood swings. Among the side effects, weight gain is the only side effect that seems to increase report with duration of tamoxifen use [20]. Since the anti-estrogenic effects of tamoxifen can cause weight gain, and weight gain increases the incidence of lipoma, tamoxifen use may have contributed to the occurrence of lipoma in the buccal fat pads. Moreover, the patient complained that both protruding cheeks became even worse after undergoing injection lipolysis including PC-DC to reduce adipose tissue in both cheeks at a plastic surgery clinic a year ago. This may have occurred because the PC-DC injection inhibited the lipolytic function of leptin, thereby leading to adipose tissue accumulation. However, no studies have been reported on the definite mechanisms related to PC-DC and lipoma occurrence, so further studies are expected.

In conclusion, when evaluating lesions suspected to be lipomas, careful attention should be paid to the patient's medication use and surgical history. Our case suggests that tamoxifen-induced weight gain and subcutaneous PC-DC injections can promote lipoma incidence and growth. Additional reports of similar cases are expected. Further research on the mechanism of fat accumulation will be necessary.

\section{NOTES}

\section{Conflict of interest}

No potential conflict of interest relevant to this article was reported.

\section{Ethical approval}

The study was approved by the Institutional Review Board of Inje University (IRB No. 2021-08-038). 


\section{Patient consent}

The patient provided written informed consent for the publication and the use of her images.

\section{ORCID}

In Suk Koh https://orcid.org/0000-0001-6182-9320 Jin Woo Kim Ji Young Yun https://orcid.org/0000-0002-7660-843X Eui Han Chung Young Il Yang Hook Sun https://orcid.org/0000-0001-8129-1417 https://orcid.org/0000-0002-6581-4502 https://orcid.org/0000-0002-6926-9759 https://orcid.org/0000-0003-0104-2598

\section{Author contribution}

Conceptualization: Jin Woo Kim, Ji Young Yun, Hook Sun. Data curation: In Suk Koh, Eui Han Chung, Young Il Yang, Hook Sun. Methodology: Hook Sun. Project administration: In Suk Koh. Writing - original draft: Hook Sun. Writing - review \& editing: In Suk Koh, Jin Woo Kim, Ji Young Yun, Eui Han Chung. Investigation: In Suk Koh, Young Il Yang.

\section{REFERENCES}

1. El-Monem MH, Gaafar AH, Magdy EA. Lipomas of the head and neck: presentation variability and diagnostic work-up. J Laryngol Otol 2006;120:47-55.

2. Aita TG, Bonardi JP, Stabile GA, Pereira-Stabile CL, Faverani LP, Hochuli-Vieira E. Lipoma on the lower lip. J Craniofac Surg 2017;28:e750-1.

3. Chia C, Rovaris D, Fontana R. Giant lipoma of the buccal fat pad: case report and literature review. Rev Bras Cir Plast 2001; 31:112-7.

4. Fomete B, Amalimeh B, Rowland A, Uche OA. Lipoma of the floor of the mouth: case report and review of the literature. Case Study Case Rep 2013;3:65-70.

5. Kim T, Kim J, Choi J, Oh S, Kwon S, Jeong W. Meningothelial hamartoma of the scalp. Arch Craniofac Surg 2020;21:180-3.

6. Choi JS, Han HH, Rhie JW. Intermuscular lipoma in the posterior triangle of the neck. Arch Craniofac Surg 2015;16:99-101.

7. Trento GD, Stringhini DJ, Rebellato NL, Scariot R. Extra-oral excision of a buccal fat pad lipoma. J Craniofac Surg 2017;28: e226-7.
8. Jang N, Shin HW, Kim J, Yoon KC. A case report of Madelung's disease. Arch Craniofac Surg 2020;21:305-8.

9. Kim JH, Ahn $\mathrm{CH}$, Kim $\mathrm{KH}$, Oh $\mathrm{SH}$. Multifocal intraosseous calvarial hemangioma misdiagnosed as subgaleal lipoma. Arch Craniofac Surg 2019;20:181-5.

10. Burns A. Observations on the surgical anatomy of the head and neck. Edinburgh: Thomas Bryce \& Co.; 1811.

11. Cameron AL. Lipoma of the corpus adiposum buccae: review of the literature and report of a case. JAMA 1921;76:778-81.

12. Goutzanis L, Chliaoutakis A, Kalyvas D. Bilateral buccal space lipoma: a rare case presentation. J Clin Exp Dent 2019;11:e55860.

13. Kolb L, Yarrarapu SN, Ameer MA, Rosario-Collazo JA. Lipoma. In: StatPearls [Internet]. Treasure Island: StatPearls Publishing; 2021 Jan [cited 2021 Oct 27]. Available from: https:// www.ncbi.nlm.nih.gov/books/NBK507906/.

14. Nguyen MC, Stewart RB, Banerji MA, Gordon DH, Kral JG. Relationships between tamoxifen use, liver fat and body fat distribution in women with breast cancer. Int J Obes Relat Metab Disord 2001;25:296-8.

15. Thomas MK, D'Silva JA, Borole AJ. Injection lipolysis: a systematic review of literature and our experience with a combination of phosphatidylcholine and deoxycholate over a period of 14 years in 1269 patients of Indian and South East Asian origin. J Cutan Aesthet Surg 2018;11:222-8.

16. Reeds DN, Mohammed BS, Klein S, Boswell CB, Young VL. Metabolic and structural effects of phosphatidylcholine and deoxycholate injections on subcutaneous fat: a randomized, controlled trial. Aesthet Surg J 2013;33:400-8.

17. Bartness TJ, Liu Y, Shrestha YB, Ryu V. Neural innervation of white adipose tissue and the control of lipolysis. Front Neuroendocrinol 2014;35:473-93.

18. Durak D, Eren B. Pericardial lipoma: an autopsy case and review of the literature. J Forensic Sci 2007;52:949-50.

19. Paunipagar BK, Griffith JF, Rasalkar DD, Chow LT, Kumta SM, Ahuja A. Ultrasound features of deep-seated lipomas. Insights Imaging 2010;1:149-53.

20. Lorizio W, Wu AH, Beattie MS, Rugo H, Tchu S, Kerlikowske K, et al. Clinical and biomarker predictors of side effects from tamoxifen. Breast Cancer Res Treat 2012;132:1107-18. 